\title{
ROBERT VENTURI Y EL ANÁLISIS DE LA ARQUITECTURA DE ALVAR AALTO
}

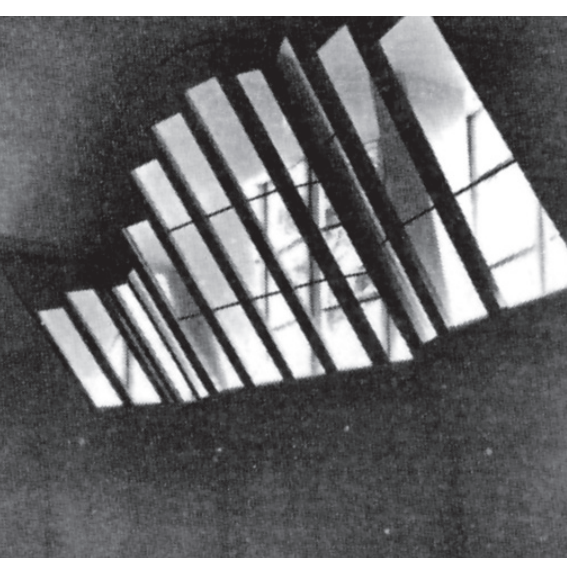

\author{
Daniel García-Escudero y Berta Bardí i Milà
}

Robert Venturi and the analysis of Alvar Aalto's architecture

Boletín Académico. Revista de investigación y arquitectura contemporánea

Escuela Técnica Superior de Arquitectura. Universidade da Coruña elSSN 2173-6723

wuw.boletinacademico.com

Número 3 (2013)

Páginas 49-56

Fecha de recepción 19.11.2012

Fecha de aceptación 16.01.2013

\section{Resumen}

En el año 2012 se han cumplido cincuenta años de la redacción del libro Complexity and Contradiction in Architecture, publicado en 1966, aunque redactado mayoritariamente en 1962. Este artículo aprovecha la efeméride para rescatarlo y focalizar ahora la mirada en la obra de Alvar Aalto, uno de los arquitectos que, en palabras del propio Venturi, más le influyó: "Aalto es para mí la fuente más rica para aprender por su arte y su técnica”. El análisis de Venturi representa una alternativa a la visión "clásica" que se construye sobre Aalto durante los cincuenta, y marca el camino de estudios posteriores.

\section{Abstract}

In 2012, the book Complexity and Contradiction in Architecture has been attained fifty years, published in 1966, although written mostly in 1962. This article takes advantage of this occasion to rescue it and to focus the gaze now on Alvar Aalto's work, one of the architects that moreinfluence him. In Venturi's words: "Aalto is the richest source for me to learn by his art and his technique". The analysis of Venturi represents an alternative to the "classical" vision about Aalto during 1950 and marks the path of later studies.

\section{Palabras clave}

Venturi, Aalto, Análisis, Arquitectura, Orden

\section{Keywords}

Venturi, Aalto, Analysis, Architecture, Order 


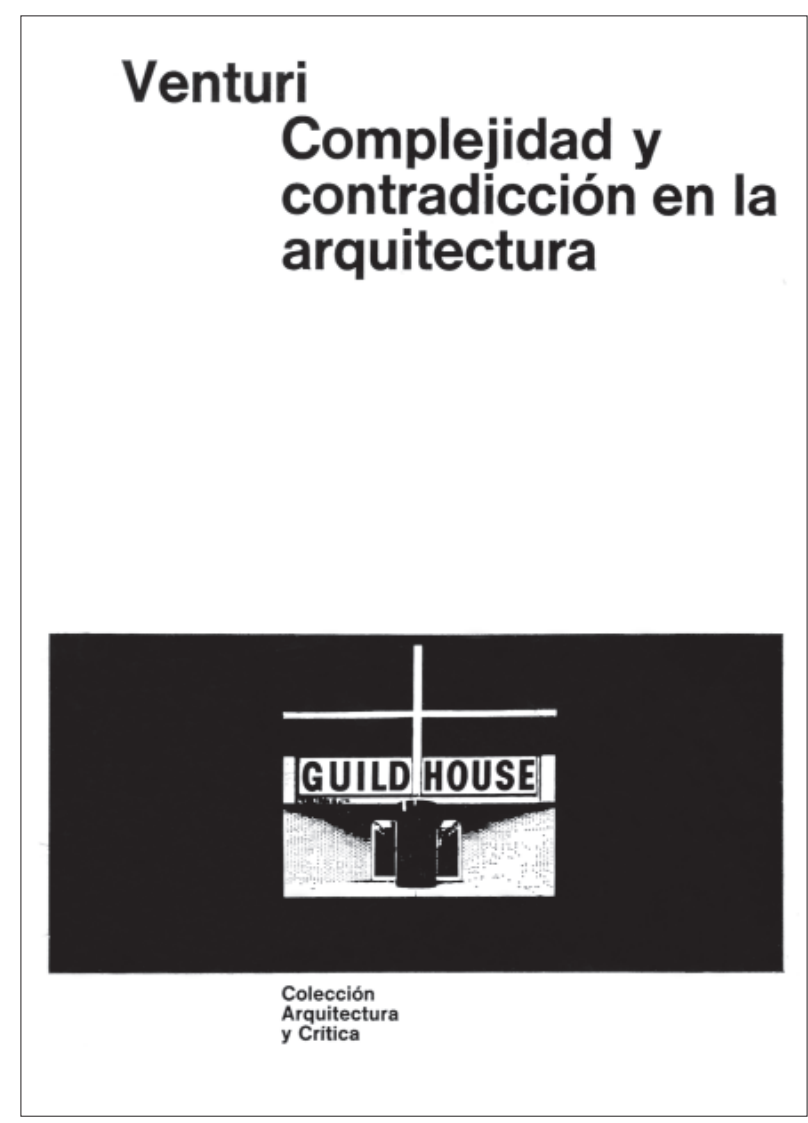

1 Robert Venturi, Complejidad y contradicción en la arquitectura (Barcelona: Gustavo Gili, 1974), portada

En 2012 se han cumplido cincuenta años de Complexity and Contradiction in Architecture ${ }^{1}$, uno de los libros más influyentes de la arquitectura ${ }^{2}$ (Fig. 01). Aunque se publica en 1966, se escribe mayoritariamente durante 1962, como indica Robert Venturi en los agradecimientos. Este artículo aprovecha la efeméride para dirigir de nuevo nuestra atención hacia el libro, y plantea su revisión a través de uno sólo de los arquitectos que menciona y analiza: Alvar Aalto.

Se escribe en un momento en el cual comienza a forjarse la imagen canónica de Aalto, con la mayoría de las obras importantes ya construidas o en proceso. Esas obras no capitalizan el libro, aunque están en la base de sus argumentos, como Venturi confesará con motivo de la muerte de Aalto: «El trabajo de Aalto ha resultado el mejor de todos los arquitectos modernos. Es para mí, la fuente más rica para aprender por su arte y su técnica» ${ }^{3}$.

Repasar las reflexiones de Venturi nos permitirá entender mejor los mecanismos proyectuales de Aalto. Además, comprobaremos cómo anticipa algunos de los principales estudios que se realizarán sobre Aalto, como los desarrollados por Demetri Porphyrios o Antón Capitel.

\section{EL CONTEXTO CRÍTICO}

Durante los años cincuenta los textos críticos sobre Aalto son escasos y se ciñen, sobre todo, a los de Sigfried Giedion, que lo menciona sólo de pasada en la primera edición de «Space, Time and Architecture»", en 1941. Una década después, en 1950, publica el artículo "Alvar Aalto" en la revista The Architectural Review que se incluye en la versión revisada del libro de 1952 , bajo el título "Alvar Aalto: Elemental and Contemporary». En él señala a Aalto como representante de lo irracional-orgánico, y lo tilda de genio que trabaja a través de la inspiración. Finalmente, en la quinta edición, en 1967, titula el capítulo: "Alvar Aalto: Irrationality and Standardization».

Estos escritos construyen la imagen canónica de Aalto, al que se transforma en el héroe que supera la primera modernidad. Este punto de vista es recogido por dos de los estudiosos más tenaces de su obra, Leonardo Mosso y Göran Schildt. Ambos perpetúan la visión irracionalorgánica, y contribuyen más a realizar una hagiografía que a profundizar en su arquitectura. Por el contrario, Venturi se aleja de estos tópicos:"Giedion ha escrito sobre la singular 'combinación de la estandarización con la irracionalidad, de manera que la estandarización no es ya la que manda, sino la que sirve' de Aalto. Prefiero pensar en el arte de Aalto como contradictorio en lugar de irracional —un sabio reconocimiento de lo circunstancial y de lo contextual» ${ }^{6}$ (Cap. 6, 72).

No obstante, los arquitectos más mencionados en Complexity and Contradiction in Architecture son Le Corbusier y Kahn. Sin embargo, Vincent Scully, en la introducción a la primera edición, afirma que «Venturi evita las preocupaciones estructurales de Kahn a favor de un método funcional más flexible que se acerca más al de Alvar Aalto». De manera que Venturi «valora sobre todo las acciones de los hombres y el efecto de las formas artísticas sobre su espíritu» ${ }^{7}$.

Estos comentarios no resultan extraños si se tiene en cuenta que sólo unos años antes del libro de Venturi, Scully publica Modern Architecture: The Architecture of Democracy $^{8}$. En él valora el afán de Aalto por proyectar volúmenes capaces de ser al mismo tiempo funcionales y expresivos. Así, la complejidad de sus formas realza la actividad de las personas, su bienestar físico y psicológico: «A diferencia del nuevo clasicismo, [Aalto] se interesa por lo que la gente hace $y$, a diferencia de la obra de Wright, no trata de suavizar sus acciones en estructuras rítmicas únicas»?. 
se consiguió mediante las sutilezas y la prexision de su distorsionada peometria y las contradicciones tensiones inherentes en su orden. El templo doriti puede conscguir una aparcnte simplicidad a trats

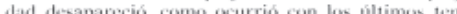
Lit compleiidad no nicea la simplificasion valich que es parte del proceso de análisis, e incluso un método de conseguir la misma arquitectura conpleja. "Nosotros supersimplificamos un hecho determinado cuando to caracterizamos desde el punto de vista de un inters deterininados Pero esta claanalitico de conseguir un arte complejo. No debe confundirse con un objetive.

Sin embargo, una arquitectura de la complejidad la contradicción, no quiere decir un expresionismo pintoresco o subjetivo. Una falsa complejidad ha replicado recientemente a la falsa simplicidad de una primitiva arquitectura moderna. Fomenta una arquitctura phoresca simbica -que Minoru Yamalismo nucvo an desconectado de la experienci como el antiguo cuito a la simplicidad. Sus compli cadas lormas no reflejan autenticamente lus progra mas complejos, y su compltcada ornamentacion, aunque depende de las técnicas industriales en su eje cucion, es triamente reminiscente de formas originat mente creadas por tecricas artesanales. Los adornos

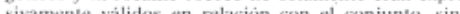

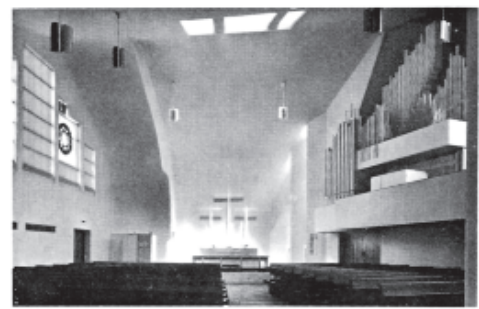

que surgicron de una ostentación de la habilidad manuar y expresaron una vitalidad derivada del contacts directo y da indina

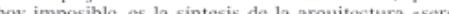
has a pesar del superticial parecido entre cllas. Pero Si la exubtrancia no es la característica de nuestro arte, es la tensión, en lugar de la sserenidado, la que aparece como tal.

Los mejores arquitectos del siglo $\mathrm{xx}$ generamenplicin rechazado la simplificacion - esto es, la simplicidad a trates de la reduction para promore de Alvar Aalto y Le Corbusier favien a meneth is nora sus pecritos polómicos) Pero las caracterist cas de complejidad y contradicción en sus obras ggnoran o se entienden mal. Por ejemplo, los crit cos de Aalto lo han alabado principalmente por sio sensibilidad a los materiales naiturales y por sus be hos detialles y han considerado el conjunto de ta composición premeditadamente pintoresca. Yo no Al Iraducir sus volumenes la auténtis complejida de una planta dividida en tres partes y la forma del mo justificado/diferente del pintoresquismo delibe rado de la estructura y de los espacios dejados a azar de la reciente iglesia de Glovanni Micheluce en la Autostrada del Sole (4). La complejidad de Aalto en lupar de ser un ardid justificado sólo por ol deso de expresion. Aunque ya no discutiremos mis so

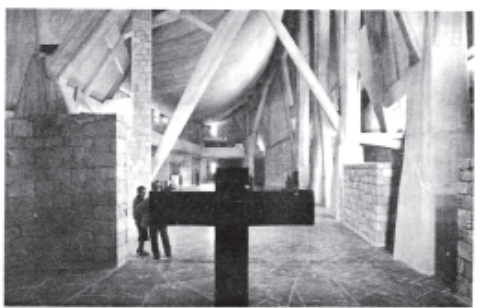

combinaciones similares de direcciones y ritmos contrastantes en cotumnas, pitares, muros y cubier-

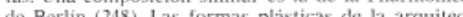
de Bermediternes indigena (249) son sencillas en lextura pero los rectángulos, diagonales y segmentos se combinan llamativamente. El tocador de Gaud de la Casa Güell (250) representa una orgia de dua lidades contrastantes en forma: la inflexión y continuidad extremas se combinan con contigüidades discontinuidades volentas, curvas complejas y sim.

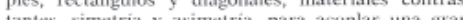
cantidad de funciones en un todo $A$ escala de mue bles, el sentido prevalente de lo eyuivoco se expresa en la silla ilustrada en (103). La configuración posterior es curva y la delantera es rectangular. No es diferente en su dificil composición a la silla de madera curvaca de Aalto ilustrada

Intrinseco a una arquitectura det antagonismo es

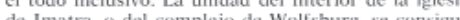

no a través de la supresion o la exclusion sino a traves de la inclusion dramatica de las partes con-

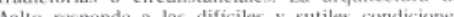

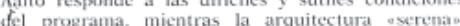
por orra parte, se esfucrza en simplificartas.

Sin embargo, el compromiso con el conjunto en una arquitectura de la complejidad y la contradicciòn no excluye al edificio que no está resuclto. Los poetas y dramaturgos aceptan los dilemas sin solucion. La vatidez de las preguntas y la vivacidad de significado ch to que hate de sus obras un arte ch

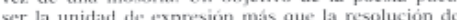
contenido la coculiera contemporánea es a menud ragmentaria y huy apreciames las Pietàs inacabis. das de Miguel Angel max que sus obras anteriores, porque su contenido se suglere, su expresion es más inmediata y sus tormas se completan mas alla de ellas mismas. Un cdificio tambien pacde scr mas y su forma.

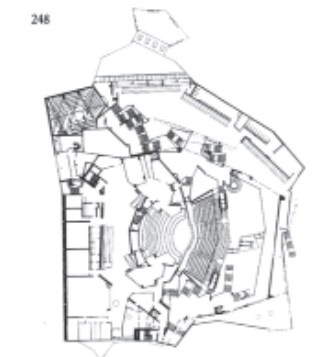

164

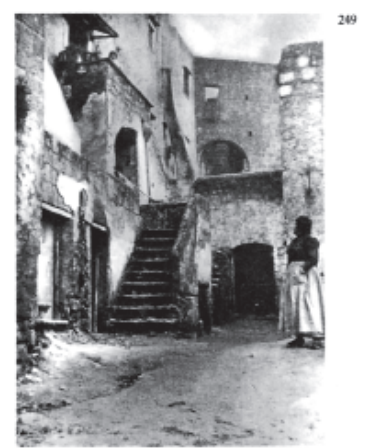

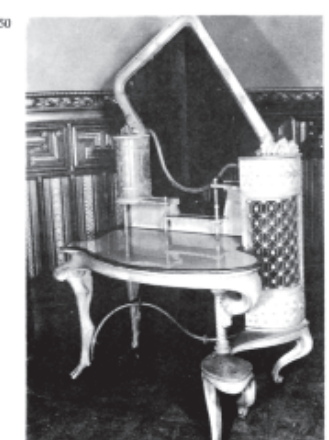

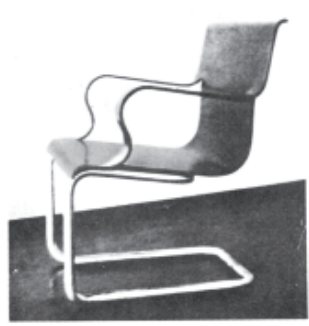

2-3 Robert Venturi, Complejidad y contradicción en arquitectura, Gustavo Gill, 1974, págs. 30-31 y 164-165 


\section{EL ANÁLISIS DE LA OBRA DE AALTO}

Seguramente sea Aalto uno de los pocos arquitectos que hayan practicado muchas de las estrategias que después Venturi investiga y ejecuta. En los proyectos de Aalto se puede encontrar una arquitectura capaz de aceptar contradicciones, y que responde con complejidad al lugar y al programa. Precisamente esta relación entre forma y programa es la primera estrategia que Venturi apunta en su libro. Junto a esta relación, también señala la existente entre orden e irregularidad, y el desencaje entre el interior y el exterior en sus proyectos ${ }^{10}$.

\section{Forma y programa}

Una característica que comparten muchas de las obras de Aalto es la necesidad de resolver programas exigentes y diversos. Es frecuente que sus edificios deban resolver la coexistencia de partes públicas y privadas, de zonas abiertas con espacios fuertemente compartimentados. Estos requisitos suelen condicionar la forma, cuya complejidad final no es arbitraria, sino que atiende a las necesidades de uso. Venturi menciona la iglesia de Imatra como ejemplo:

«Yo no considero pintoresca la iglesia de Imatra. Al traducir sus volúmenes la auténtica complejidad de una planta dividida en tres partes y la forma del techo acústico, esta iglesia supone un expresionismo justificado. La complejidad de Aalto forma parte del programa y estructura del conjunto en lugar de ser un ardid justificado sólo por el deseo de expresión» (Cap. 2, 31) (Fig. 02).

Y como no podía ser de otra manera, esa complejidad es inclusiva, esto es, capaz de admitir lo diverso y lo irregular; una arquitectura que rehuye la simplificación como objetivo:

«La unidad del interior de la iglesia de Imatra, o del complejo de Wolfsburg, no se consigue a través de la supresión o la exclusión sino a través de la inclusión dramática de las partes contradictorias o circunstanciales. La arquitectura de Aalto responde a las difíciles y sutiles condiciones del programa, mientras la arquitectura 'serena', por otra parte, se esfuerza en simplificarlas» (Cap. 10, 164-165) (Fig. 03).

Lejos está aquí aquella antigua voluntad miesiana de "crear un espacio que sirva para cualquier función», como apunta Fullaondo en un artículo de Nueva Forma del mismo año en que se publica el libro de Venturi, 1966. En el texto, Fullaondo reflexiona sobre la peligrosa generalización espacial de Mies, que se vuelve parodia cuando muchos acólitos la interpretan como "crear un espacio que no sirva para absolutamente nada ${ }^{11}$.

Cabe matizar, sin embargo, que existen en Aalto ciertos patrones organizativos y formales previos e independientes al programa, como la disposición claustral. Esta disposición gobierna proyectos tan distantes como el pabellón finés en París y el centro cultural de Wolfsburg. Aalto, con sutiles quiebros, pliegues o deslizamientos los modifica, sin mermar sus leyes básicas, ni la unidad de la obra.

\section{Orden e irregularidad}

Tampoco Le Corbusier se ciñe a la idea de orden que subyace en las obras de Aalto. El par retícula-gesto que ordena los proyectos corbuserianos, está más cerca de la homogeneidad de Mies que de la heterogeneidad de Aalto.

"Le Corbusier en la Villa Savoye adapta las irregularidades circunstanciales y excepcionales a un método, por otro lado rígido y dominante [la retícula]. Pero Aalto, en contraste con Le Corbusier, casi parece crear el orden de las irregularidades, como puede verse en el Centro Cultural de Wolfsburg (...) Mies no permite que nada se introduzca en la regularidad de su orden del punto, línea y plano» (Cap. 6, 64).

Donde sí podrían hacer frente común Aalto y Le Corbusier es en la manera de ejecutar ese deseado orden. Mies aspira a una claridad sólo alcanzable a través de la geometría ortogonal y la retícula universal. Aalto y Le Corbusier no rechazan la tensión y el equilibrio que producen la convivencia de diversas geometrías, dictadas por el programa o la relación con el lugar.

«Mies y Johnson rechazan todas las contradicciones de la estructura diagonal (...) En muchas obras de Le Corbusier y Aalto, sin embargo, se consigue el equilibrio o quizá la tensión entre la rectangularidad de las técnicas estándar y la línea diagonal. En sus apartamentos de Bremen, Aalto ha tomado el orden rectangular de la unidad básica de vivienda de Le Corbusier (...) y lo ha distorsionado en diagonales para orientar la vivienda hacia el sur» (Cap. 7, 80) (Fig. 04).

Estas colisiones de órdenes dispares o supercontigüidades son reivindicadas por Venturi como una manera de quebrantar las normas, de romper las reglas compositivas clásicas. Sin embargo, esto no supone la desapari- 
lia (75) puede verse que Mies y Johnson rechazan todas las contradicciones de la estructura diagonal en lavor de una expresion de la estructura rectangular. Kahn una vez dijo que el edificio Seagram era come una señora guapa con un corsé escondido. Kahn, en contraste expresa la esisctura, pero a expensas de bićn hay que decirlo de los expacios para ta gente. En muchas obras de Le Corbusier y Aalto, sin embargo, se consigue el equilibrio o quizá la tensión entre la rectangularidad de las técnicas estandard y la linea diagonal que expresa las condiciones excep. cionales. En sus apartamentos de Bremen (76) Aalto ha tomado el orden rectangular de la unidad básica ace vivienda de Le Corbusicr, con la que levanta sus sionado en diagonales para orientar la vivienda hacia el sur en busca de la luz y de la vista, Las escaleras que dan al norte y las are cen estrictamente rectangulares en planta. Aun en las unidades de los extremos la rectangularidad y la regularidad det espacio se mantiene. $Y$ en el Centro Cultural de Wolissurg de Aalto (78), la configuración Chectangular de la composicion alobal apenas se man.

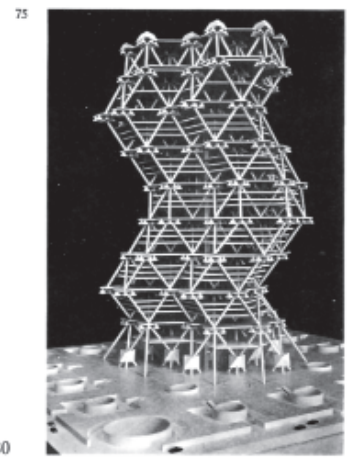

tiene, cuando organiza las formas necesariamente dia-

gonales de los auditorios.

Esto es diferente del proyecto de la Goldenber House de Kahn (79) donde la diagonal excepcional es en parte un elemento de la disposicion estructural yespacios en las esquinas del edificio, que evital are una fachada se solape sobre la otra-

gularidad de su orden del punto, linea y plano de sus pabellones siempre bien acabados. Si Wright camufla sus excepciones circunstanciales, Mies las excluye: menos es mas. Desde 1940 Mies no ha empleado una diagonal circunstancial y en su serie de proyec nal es una función de la planta libre en lugar de una condición de lo circunstancial. Debido a que la diagonal es dominante en lugar de excepcional y porque está libremente contenida en su estructura rectangular, hay poca tensión entre las diagonales y los rec tángulos. Los tirantes diagonales de las estructura de lus edificios de grani luz de Mites

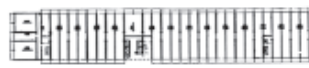

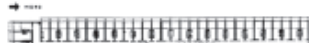

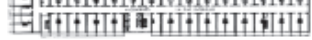
E-
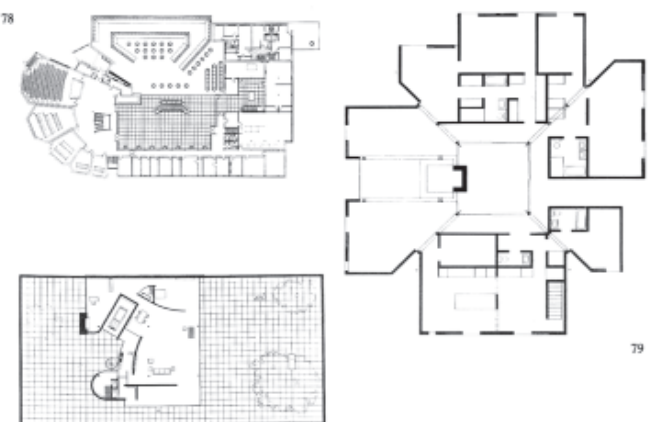

30 a gran escala detrás de una cosa a menor escala. En S. Maria della Pace (150) la superposición de elementos que cierran, que son sucesivamente convexos, perposiculaes y hrogo concavos, los convier. hacer funcionar las transiciones entre el exterior y cl interior.

La planta de la Villa Savoye es un ejemplo de contención de muchas complejidades dentro de un marco rígido. Algunas plantas de otras casas suyas de los años 20 nos sugieren que se empezó a trabajar por la estructura para pasar lacgo al interior. de la Hith Court de Chandienth (151) Del mismo modo la parte trasera de la Low House de McKims. complejidades dentro de una lachada rigida. El severo tejado y la envoltura de la pared de la casa

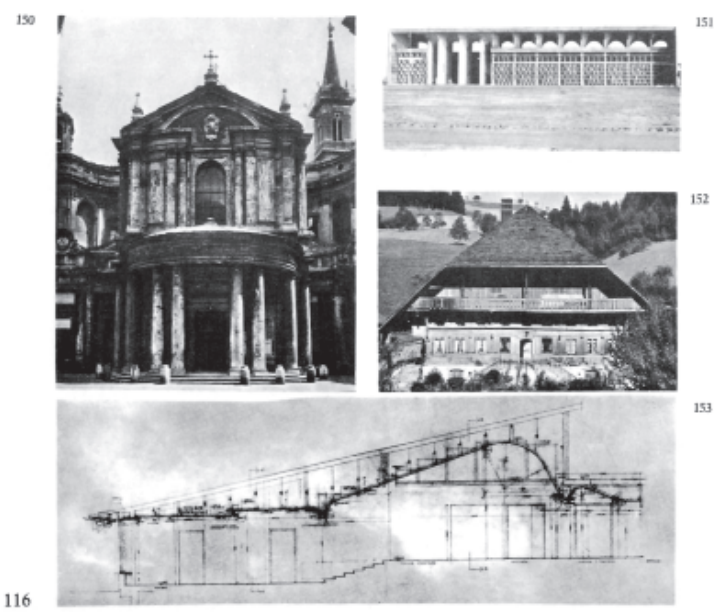

contienen espacios $y$ niveles de planta complejos que se expresan mediante la variación de las posiciones de las ventanas. De manera parecida, la única
cubierta que cubre la casa de tipo Emmental en cubierta que cubre la casa de tipo Emmental en
Suiza (152) y el tejado con pendiente constante de la Maison Carré de Aalto (153), contradicen los es. pacios interiores que están debajo. Y tensiones similares se producen en la fachada trasera de Mi. Vernon (71) por el contraste de las ventanas En lia fachada lateral de Easton Neston de Hawksmoor (154), las ventanas están colocadas por requerimientos particulares inleriores que desal ian el orden horizontal. La complejidad dentro de un marco rigido ha sido una idea muy extendida. Se encuentra en cesi (155) y la composicion de un nicho de Mien Angel (156) Otros cjemplos más puramente expresivos son las fachadas de la iglesia parroguial de

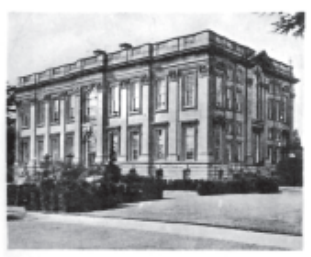

154
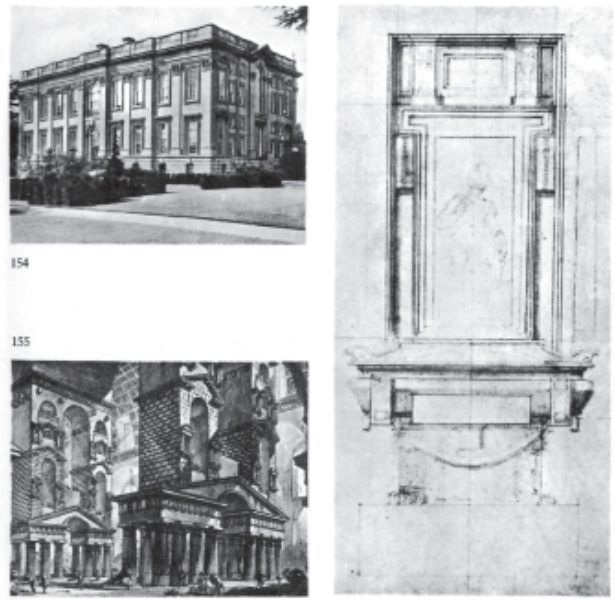

11

4-5 Robert Venturi, Complejidad y contradicción en arquitectura, Gustavo Gili, 1974, págs. 80-81 y 116-117 
ción del orden general del conjunto, sino la percepción de un orden quebrado, pero al fin y al cabo un orden. En algunas obras de Aalto, esa coexistencia de matrices formales diferentes es solventada por otro de los mecanismos que apunta Venturi: la inflexión.

Este procedimiento de construcción de orden ya es mencionado por Arthur Trystan Edwards en Architectural Style $e^{12}$, donde lo define como «fenómeno propio de las composiciones complejas en las cuales un compromiso especial con el todo refuerza las partes", es decir, la deformación de una pieza para ajustarse a otra. Una mirada atenta a los proyectos de Aalto pone en evidencia, como ha apuntado también Joaquim Español, que «las líneas radiales se adaptan, con una elegante inflexión, a las directrices de las dependencias rectangulares», asegurando la consistencia de las partes con el todo ${ }^{13}$.

\section{Interior y exterior}

Ante estas cuestiones, cabría preguntarse si estas estrategias para ordenar los espacios y las formas son idénticas en el interior y en el exterior o si, por el contrario, son dos mundos separados que responden a planteamientos diferentes. Venturi lo deja claro:

«El propósito esencial de los interiores de los edificios es encerrar, en lugar de dirigir el espacio y separar el interior del exterior. La función de la casa de proteger y proveer el aislamiento psicológico y físico es una función antigua» (Cap. 9, 111).

En Aalto, no es difícil encontrar ejemplos en los que el contorno interior y el perfil exterior difieran y generen lo que Venturi bautiza como «espacio residual». Este espacio, en apariencia inerte, se convierte en ocasiones en un catalizador de la luz o de los recorridos. Los ejemplos son múltiples, aunque Venturi señala dos: el hall de la casa Louis Carré y su curvilíneo techo, absolutamente diferente del plano inclinado de la cubierta; y la iglesia de Imatra, que desdobla sus fachadas al estilo de las construcciones barrocas. Tanto el primer caso como el segundo muestran la libertad con la que Aalto maneja el perímetro de sus edificios.

«El complejo 'oculus' y las otras aberturas de la cúpula interior de $\mathrm{S}$. Chiara de Brà definen el espacio residual, que está abierto para elaborar el espacio y manipular la luz. La separación de las aberturas de las ventanas interiores y exteriores en la iglesia de Imatra de Aalto modifica de una manera similar la luz y el espacio" (Cap. 10, 129-130) (Fig. 06).
En los innumerables ejemplos que se convocan en el libro, desde el templo de Karnak hasta Santa Maria dell'Assunzione en Arricia, Venturi muestra su fascinación por la serie escalonada de cosas dentro de cosas o de cerramientos dentro de cerramientos, que envuelven el espacio. Aunque no se acude al Museo de Aalborg o a la Ópera de Essen, ambos proyectos encajan en esa percepción de que Aalto genera el espacio a base de la sucesión de ámbitos, unos dentro de otros, que de forma progresiva conducen a un centro desde donde se genera la obra.

\section{CONCLUSIONES}

Son características propias de las arquitecturas que Venturi reivindica, especialmente las de Aalto, las asimetrías y las yuxtaposiciones, los quiebros y las rupturas, los fragmentos y los cambios de escala. Todo ello sin dejar de valorar el compromiso con el dificil conjunto como una pretensión de unidad que no renuncia a la autonomía e independencia de las partes. En los ejemplos, desde el barroco inglés de Vanbrugh hasta Aalto, la unidad de la obra no conlleva una jerarquización que obvie la autonomía y libertad de los elementos y las partes. Así, esas partes, autónomas y con funciones dispares, contribuyen al conjunto sin necesidad de ser incluidas en férreas estructuras portantes o formales (Fig. 07).

Precisamente, esta forma de mirar la arquitectura de Aalto es la que se ve reforzada en los estudios de Demetri Porphyrios y Antón Capitel. Ya sea a través del término heterotopia que utiliza Porphyrios ${ }^{14}$, o a través del principio de composición por partes o elementos que recoge Capitel $^{15}$, la arquitectura se muestra aludiendo a un orden donde las diferentes piezas de un edificio o un espacio urbano se presentan por separado, sin una estructura común que las unifique. Frente a la unidad, la plenitud y lo lineal que representan las arquitecturas donde orden y geometría se solapan, las obras aaltianas se originan a partir de lo múltiple, lo profundo y lo complejo.

Asimismo, para completar esta interpretación cabría preguntarse por los mecanismos de reconstrucción formal y perceptiva de las diferentes partes que componen sus obras. Aunque se trate de una arquitectura diversa y compleja, finalmente se presenta de manera unitaria y coherente. En este sentido, resulta útil apuntar dos mecanismos de mortero, de unión, como son el espacio central y el recorrido perimetral o envolvente. Cuando nos movemos por las obras de Aalto lo solemos hacer 
to para elaborar el espacio y manipular la luz. Li separacion de las aberturas de las ventanas interiores y exteriores en la.iglesta de Imatra de Aalto (192) modica de una manera similar la luz y el espacio. tectura reciente.

Las bóvedas de madera del siglo xvil de las sinagogas polacas (193), que imitan la albañilería, creari forros cerrados en la sección superior. En contraste con los ejemplos anteriores su espacio residual es cerrado. El volurnen cerrado, determinado princi. palmente por las fuerzas espaciales exteriores max que por la cstructura instricseca de la forma, es casi el original Podium para conciertos de Aalto (194) compuesto de una estructura de pich-armazon de El espacio residual enmedio de espacios dominan tes, con grados diversos de abertura, puede darse a
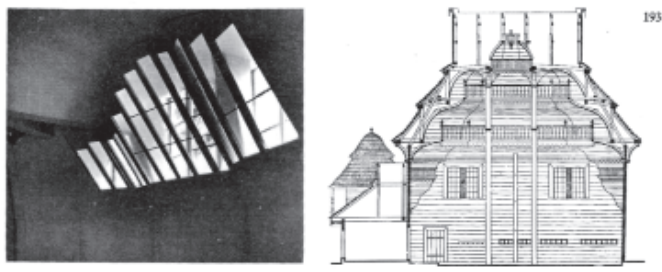

130

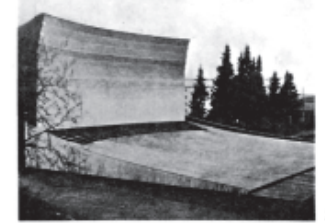

escala de ciudad y es una caracteristica de los fóros $y$ otros complejos del urbanismo romano. Los espa cios residuales no son desconocidos en nuestras ciudades. Estoy pensando en los cspacios abiertos bajo alrededor de ellos. En vez de reconocer y usar esta clase de espacios los hemos convertido en aparca. mientos o pequenas zonas de hierba-tierras de nadie entre la escala regional y la local.

El espacio residual que está abierto podria lla marse svolumen abierto". El aespacio sirvienter de Kahn, que algunas veces, guarda el equipo mecánico barroca diferente del exterior. Aldo van Eyck ha dicho: arquilectura deberia concebirse camo una configa ración de lugares intermedios claramente definidos Esto no implica una transformación continua o un aplazamiento interminable del lugar y la ocasión Por el contrario, implica un rompimiento con el concepto contemporaneo (digamos enfermedad) de ta las articulaciones entre espacios, es decir, entre el exterior y el interior, entre un espacio y otro (entre una realidad y otra). En su lugar la transición debe articularse por medio de lugares intermedios defi. nidos que permiten el conocimiento simultáneo de to que es significativo al otro lado. Un espacio inter medio en este sentido proporciona el terreno comú donde las polaridades conelictivas pueden ser feno

El espacio residual algunas veces es torpe. Como siempre un espacio sobrante, supeditado o otro. Es importante. Las caracteristicas, los contrastes y las tensiones inherentes a estos espacios, quedan quiza bien expresadas en la declaración de Kahn que *u edificio deberia tener tanto espacios malos como

El cerramiento redundante, como las complcjidades dentro de un marco, son raros en nuestra la obra de Le Corbus excepciones significativas, moderna ha tendido a ignorar tales ideas espacialcs complejas. El autility cores de Mies o de Johnson

la necesidad exterior contrastante de una interrupción espacial en la calle. En la parte frontal del edi. ficio el espacio exterior es más importante. Detrás de la fachada, la iglesia fue diseñada de fuera hacia dentro. El espacio sobrante debido a esta contrados pabellones de Fischer von. Erlach (200) ilustran con curvas cóncavas, la primera el espacio interiordominante y, la segunda, con curvas convexas, el La Grey Walls de Lutyens (56) se adapta a un patio de entrada cuya curva está determinada por el ra dio de giro de un coche yue determina la perspec. tiva del acceso. Grey Walls es una Piazza S. Ignazio rural (201). Et exterior concavo det estudio de Aalto de Munhtieni (202) forma un anfiteatro at aire li-

200
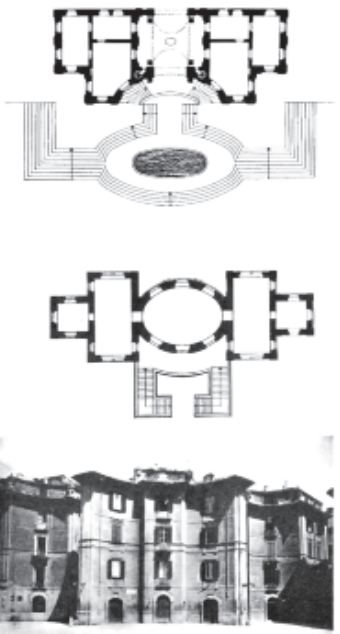

bre. Estos ejemplos crean espacios residuales inte La Karlskirche de Fischer von Erlach (42), mencionada anteriormente, combina una pequeña igle sia ovalada con una gran fachada rectangular que se adapta a su situación urbana especial mediant ana fachada falsa en lugar de un volumen. Se pre ctuce un contraste acenas contradictorio en la ia mia arcadiana de Roma (203) con la villa que has detrás. Se le ha dado a la fachada un tamaño y tor na especial para poner fin al jardin aterrazado En el santuario de Saronno (204) hay una contradic. ción tanto en estilo como en escala entre la lachada

En la iglesia barroca el interior es diferente del
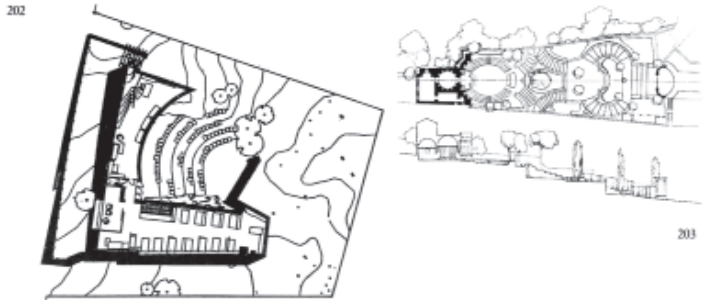

204

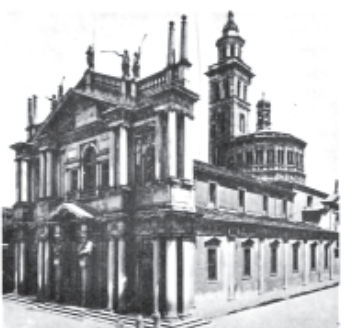

6-7 Robert Venturi, Complejidad y contradicción en arquitectura, Gustavo Gill, 1974, págs. 130-131 y 136-137 
en torno a un espacio central, cubierto o descubierto, interior o exterior, respecto al cual se generan tangencialmente tanto los recorridos como los diferentes volúmenes que los acogen, garantizando la estabilidad del conjunto.
En conclusión, Venturi es el primero en sistematizar algo que Aalto ya había transmitido en sus proyectos: que la arquitectura es una disciplina impura, un arte heterogéneo donde la unión de formas de diversa naturaleza marca el camino para el proyecto idóneo.

\section{Notas}

1. Robert Venturi, Complexity and Contradiction in Architecture (New York: Museum of Modern Art, 1966). La edición norteamericana se reedita de nuevo en 1977 y en 2002. La última edición no respeta ni el formato ni el tamaño de las imágenes de la versión original, convirtiéndose en una edición lujosa donde algunas imágenes se presentan mucho mayores. En 1972 se publica por primera vez la versión en castellano, editada por Gustavo Gili en España. Ni la edición de 1972, ni ninguna de las diversas posteriores, respeta el formato y la compaginación de la edición norteamericana. La versión espańola reduce el número de imágenes y las compagina de manera diferente, enfatizando, si cabe, la idea de colección de cosas dispares que se encuentran en el espíritu de la versión original.

2. Cf. Xavier Monteys Roig, «Robert Venturi: Complexity and Contradiction in Architecture (1966). Més no és menys». Conferencia dentro del curso «Construït amb paraules: Teories i textos d'arquitectes del segle XX» (22 abril 2009): disponible en http://hdl.handle.net/2099.2/1012. Último acceso, 23 de noviembre de 2012.

3. Robert Venturi, «Alvar Aalto», Arkkitehti 7-8 (1976): 66-67. Publicado con posterioridad en el libro del mismo autor A View from the Campidoglio: selected essays 1953-1984 (Cambridge: Icon, 1984).

4. Cf. Sigfried Giedion, Space, time and Architecture: The Growth of a New Tradition (Cambridge: Harvard University Press, 1941). Su quinta y última edición ha sido traducida al castellano y editada por Jorge Sainz Avia y la editorial Reverté: Espacio, tiempo y arquitectura: origen y desarrollo de una nueva tradición (Barcelona: Reverté, 2009).

5. Sigfried Giedion, «Alvar Aalto», The Architectural Review 2 (1950): 78-87.

6. Robert Venturi, Complejidad y contradicción en la arquitectura (Barcelona: Gustavo Gili, 1974). En este artículo se ha utilizado, tanto para los textos como para las imágenes, la segunda edición en castellano publicada por Gustavo Gili. Por tanto, a continuación no se indicará la fuente bibliográfica de las citas, sino el capítulo y las páginas donde se encuentran.

7. Cf. Robert Venturi, Complejidad y contradicción en la arquitectura, 13.

8. Vincent Scully, Modern Architecture: The Architecture of Democracy (New York: George Braziller, 1961).

9. Scully, Modern Architecture, 38. Con las palabras «último clasicismo» se refiere a las últimas obras de Mies en Estados Unidos, las cuales son objeto de crítica a lo largo del texto.

10. Cabe advertir que todos estos aspectos que apunta Venturi son recogidos y ampliados muy pocos años después en Forme et déformation des objets architecturaux et urbains, publicado por primera vez en 1978. En él se realiza una aproximación morfológica a los fenómenos arquitectónicos y urbanos de gran parte de la historia. En concreto, sobre Aalto se continúan aplicando los términos de Venturi, y se señala que la "contradicción» es la causa potencial de la «deformación» en gran parte de sus obras. Recientemente, José Ramón Alonso Pereira y la editorial Reverté han traducido, bajo la edición de Jorge Sainz, este clásico francés: Alain Borie, Pierre Micheloni, Pierre Pinon, Forma y deformación de los objetos arquitectónicos y urbanos (Barcelona: Reverté, 2006).

11. Juan Daniel Fullaondo Errazu, «Humanismo y paradoja en la obra de Mies van der Rohe», Nueva Forma-El Inmueble 9 (1966): 29-31. Publicado posteriormente en: María Teresa Muñoz Jiménez, Juan Daniel Fullaondo: Escritos Críticos (Madrid: Mairea Libros, 2007), 30-40.

12. Arthur Trystan Edwards, Architectural Style (Londres: Faber\&Gwyer, 1926). Citado por: Joaquim Español Llorens, El orden frágil de la arquitectura (Barcelona: Fundación Caja de Arquitectos, 2001), 100.

13. Cf. Español, El orden frágil, 166.

14. Cf. Demetri Porphyrios, Sources of modern eclecticism: studies on Alvar Aalto (London: Academy, 1982).

15. Cf. Antón González-Capitel Martínez, La Arquitectura compuesta por partes (Barcelona: Gustavo Gili, 2009). Más recientemente también ha publicado el libro: La arquitectura como arte impuro (Barcelona: Fundación Caja de Arquitectos, 2012). En ambos casos se trata de estudios no vinculados únicamente a Aalto, aunque se le dedica una parte de las reflexiones. Del mismo autor se puede consultar la monografía: Alvar Aalto: método y proyecto (Madrid: Akal, 1999).

Procedencia de las imágenes

Figs. 01-07. Robert Venturi, Complejidad y contradicción en la arquitectura (Barcelona: Gustavo Gili, 1974)

\section{Sobre los autores}

Daniel García-Escudero. Doctor Arquitecto por la Universitat Politècnica de Catalunya con la tesis Espacio y recorrido en Alvar Aalto. Es Profesor Asociado del Departamento de Proyectos Arquitectónicos de la ETSAB, e Investigador del grupo Form. Ha sido Personal Docente Investigador en Formación con una beca FPI UPC-Recerca (2007-2010). Ha realizado estancias investigadoras en Dinamarca (Danmarks Kunstbibliotek) y Finlandia (Alvar Aalto Academy) entre 2006 y 2009, con la beca "BE-DGR 2009 Helsinki" y la "Alvar Aalto Foundation Grant". Ha sido editor de la revista DPA, donde co-dirigió el número 26: Nórdicos (2010). Ha publicado sus investigaciones en diversas revistas extranjeras, como Massilia o Arhitectura (Bucuresti). Colabora con el blog de arquitectura Mise Au Point: Le Corbusier, yes autor en la publicación periódica PAB.Ha leído sus investigaciones en varios congresos internacionales de arquitectura y ha sido miembro del Comité Organizador del Congreso Internacional AURS, del DPA.

\section{dge1979@coac.net}

Berta Bardí i Milà. Arquitecta por la ETSAB y Profesora Asociada del Departament de Projectes Arquitectònics de la ETSAV. Forma parte del grupo de investigación $P A B$ y es miembro del equipo redactor de la revista DPA. Recientemente ha finalizado su tesis doctoral "Las casas de Arne Jacobsen: patio y pabellón". Ha sido Personal Docente Investigador en formación con una beca FPI UPC-Recerca (2006-2009) en la ETSAB. Ha realizado estancias investigadoras en Dinamarca (Danmarks Kunstbibliotek) y Finlandia (Alvar Aalto Academy) entre 2006 y 2009, con la beca "BE-DGR 2009 Copenhague" y la "Alvar Aalto Foundation Grant". Ha publicado sus investigaciones en diversas revistas como Arbitectura (Bucuresti), PABy DPA, en la que co-dirigió el número 26: DPA Nórdicos (2010). Ha leído sus investigaciones en varios congresos internacionales de arquitectura,como 3IAU en Madrid, EURAU en Nápoles, CIDUI en Barcelona, 4IAU en Valencia y AURS en Barcelona.

bertabardi@coac.net 